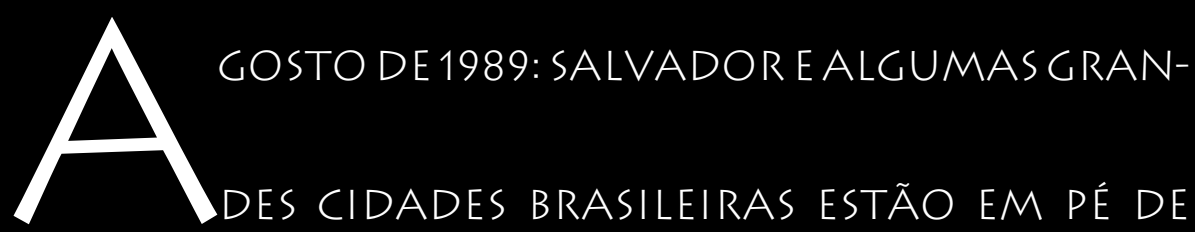

GUERRA. MOTIVO: A FLORESCENTE E RICA IGREJA UNI-

VERSAL DO REINO DE DEUS ORGANIZA, EM VÁRIAS

LOCALIDADES, CULTOS, PREGAÇÕES EM PRAÇAS PÚBLI-

CAS E ATÉ PASSEATAS, PARA DENUNCIAR HORRIPILAN-

TE BARBARIDADE - "O CANDOMBLÉ MATA CRIANÇAS

PARA OFERECER A EXU". AO SOM DE RUIDOSO TRIO ELÉ-

TRICO, COM FAIXAS DENUNCIANDO OS SACRIFÍCIOS

HUMANOS E EXCOMUNGANDO OS "ADORADORES DO

DIABO" DAS RELIGIÕES AFRO-BRASILEIRAS, MAIS DE
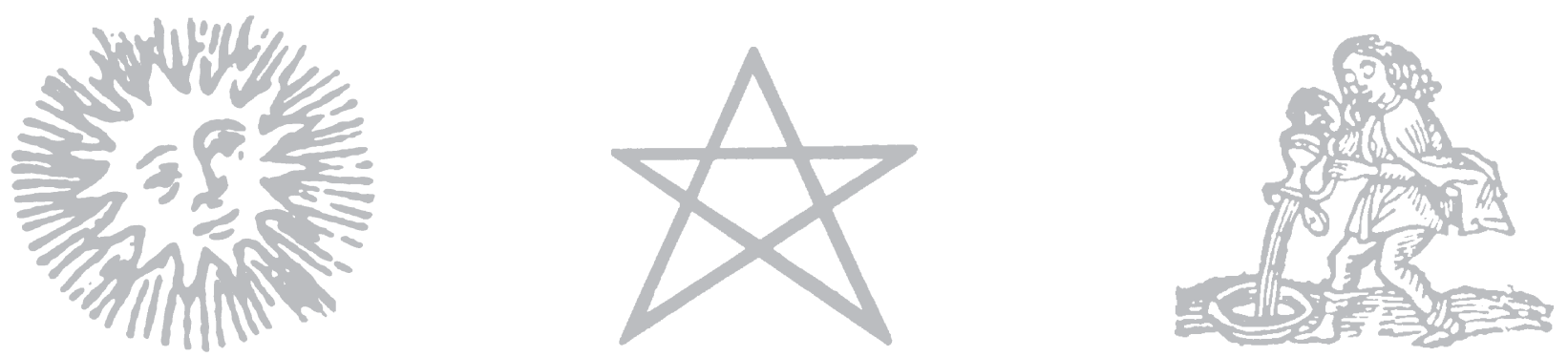


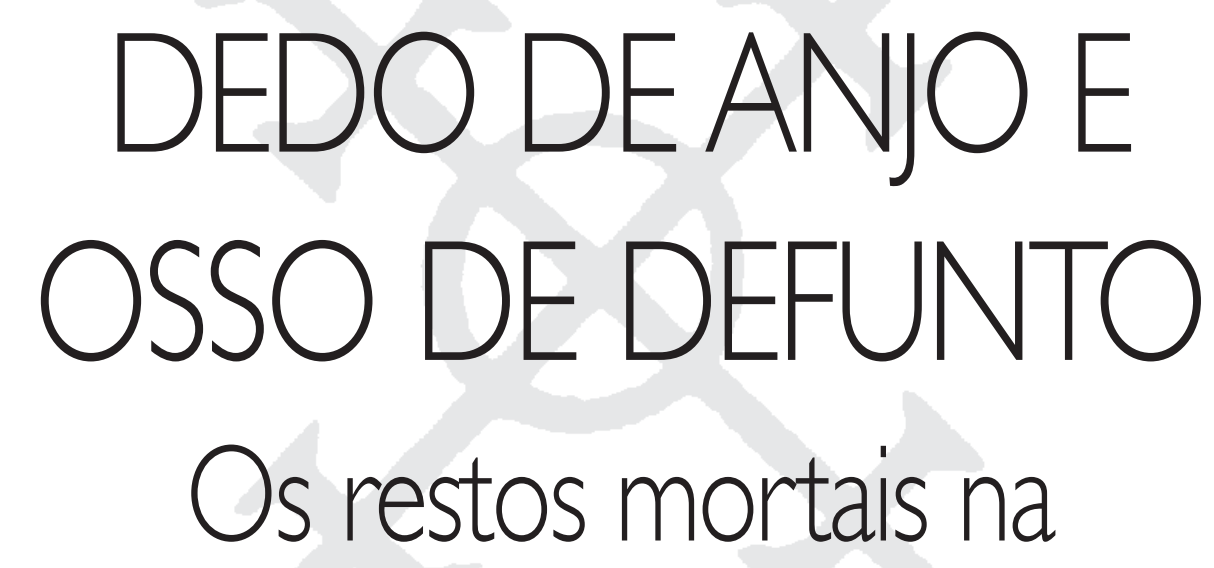

\section{feitiçaria afro-luso-brasileira}

LUIZ MOTT é

professor de

Antropologia na

Universidade Federal da Bahia e autor de, entre outros, O Sexo Proibido (1989).

Este artigo foi publicado originalmente no $D$. $O$. Leitura de $8 / 11 / 89$. 
quatro mil "crentes" dirigiram-se do Campo Grande à praça Castro Alves, no centro da capital baiana, protestando contra tais rituais satânicos. A resposta da comunidade dos cultos afro-brasileiros não tardou: várias associações negras organizaram uma passeata de protesto contra a intolerância religiosa, percorrendo o mesmo trajeto, em que denunciavam, também do alto de um trio elétrico, as calúnias divulgadas pelas "seitas subvencionadas por grupos norte-americanos", lembrando que na década passada, na praia de Ipatinga, próximo a Salvador, um grupo de evangélicos foi preso pela polícia exatamente por ter sacrificado oito crianças, que diziam estar com o demônio no corpo, episódio que ficou conhecido como "Caso Matota e Marata" (1).

Sacrifícios humanos fizeram parte integrante de inúmeras religiões antigas - inclusive do Judaísmo, conforme podemos ler no Gênesis, onde o próprio Javé pede ao Patriarca Abraão que imole seu filho primogênito, que é salvo no último instante por um anjo celestial (2). No Novo Mundo, quer entre os nativos da costa oeste dos Estados Unidos, quer nas civilizações asteca e incaica, os sacrifícios humanos faziam parte crucial dos ritos propiciatórios, e mesmo a antropofagia dos índios brasileiros pode ser interpretada como um ritual pararreligioso, posto implicarem complexa concepção simbólica relativamente à força e valentia dos inimigos que, "comungados", passavam a fazer parte dos comensais.

Consultando abundante e inédita documentação relativa aos brasileiros e colonos no Brasil, denunciados à Inquisição de Lisboa pela prática de feitiçarias, não encontramos nenhuma vez sequer a notícia de sacrifícios humanos como ritual propiciatório, num período no qual a violência dos senhores contra os escravos e dos brancos contra os índios era protegida por lei, registrando a história casos de cativos que foram açoitados até a morte (3), em que a infância era tão pouco respeitada e estimada que em meados do século XIX a Câmara Municipal de Salvador se via obrigada a prever altas multas às mães que abandonassem seus filhinhos recém-nascidos nas encruzilhadas das estradas - como explicar a inexistência então de registros de infanticídios rituais, vindo os mesmos a ocorrer somente em nossos dias, quando tais atos provocariam violenta reação popular e policial?

Se a documentação histórica do século XVI ao XIX não registra nenhum episódio de sacrifício ritual de crianças no Brasil, por outro lado encontramos na Torre do Tombo uma dezena de denúncias contra "feiticeiros" e "calunduzeiros" de ambos os sexos, que utilizariam em seus "patuás" ou "malefícios" diferentes tipos de restos mortais de seres humanos, ou, então, objetos funerários subtraídos de sepulturas ou cemitérios. É portanto sobre tais práticas macabras que nos ocuparemos aqui, mostrando com evidências históricas inquestionáveis que não fazia parte da tradição ritual afro-brasileira sacrificar crianças ou adultos como parte de seus rituais, e que mesmo a utilização de restos mortais de seres humanos não se trata de "barbarismo" de origem africana, mas procede de antigas tradições européias divulgadas no Novo Mundo pelos colonizadores brancos.

\section{$\bullet \bullet$}

Num auto-de-fé realizado pela Inquisição de Logronho, Espanha, no ano do Senhor de 1610, de 53 penitenciados, 18 eram feiticeiros, e na relação das coisas e maldades que declararam ter cometido na Seita dos Bruxos, informaram que o diabolista Miguel de Goyburn e algumas bruxas mais velhas costumavam fazer ao Demônio uma oferenda que lhe era muito grata:

"para isso, iam à noite às igrejas e desenterravam os corpos dos defuntos que já estavam gastos, e deles tiravam os ossos das articulações dos pés, as cartilagens dos narizes e todos aqueles ossinhos que existem ao redor e os miolos hediondos, e estas partes dos corpos dos defuntos recolhiam-nas em cestos e ofereciam ao Diabo, adorando-o de joelhos. E o Demônio mostrava-se muito contente, estendendo a mão comia os ossos e os miolos e repartia-os entre os bruxos presentes [...]" (4).

Pelo visto, não eram apenas Lúcifer e os demonolatras que encontravam nos ossos dos 
falecidos força e inspiração para seus rituais. A utilização sobretudo de caveiras humanas como elemento místico-ou decorativo-está associada à vida de inúmeros santos e santas do hagiológio católico medieval: diversas estampas de São Jerônimo, São Francisco de Assis, Santa Catarina de Sena, Santa Margarida de Cortona, Santa Maria Madalena, entre inúmeros outros beatos, sempre mostram uma caveirinha, quer na mão, quer nos pés, quer por sobre a mesa, ao lado desses santos. No Brasil colonial, repetindo a tradição européia, diversos foram os oradores sacros que carregavam sempre, no púlpito, uma caveira humana, ficando célebre na Bahia um episódio ocorrido na Igreja do Mosteiro de São Bento, em que o pregador, irritado com a desatenção dos fiéis às suas práticas, jogou do púlpito a dita caveira, que milagrosamente foi cair direitinho no colo de duas raparigas conhecidas por seus maus costumes.

Mais comuns na América Espanhola, embora também existentes no Brasil, foram as "capelas dos ossos", geralmente nas criptas ou cemitérios dentro das igrejas das ordens terceiras, cuja decoração das paredes era feita com os crânios e fêmures dos irmãos falecidos, que depois de raspados dos restos de carne eram empilhados artisticamente. Via de regra, todo convento, recolhimento e mosteiro tinham sempre à vista dos religiosos e religiosas um ou mais crânios, servindo como lembrança constante da efemeridade da vida terrena e da certeza da morte, muitas vezes estando gravada, quer nas paredes conventuais, quer nas entradas dos necrotérios, a lembrança: "Memento homo quia pulvis es et in pulvere reverteris". Nos conventos carmelitas a caveira ficava em cima da mesa do refeitório bem ao lado do prato da priora: "Memento mori!" ("Lembrai-vos da morte!”).

Outro episódio registrado na história sacra da Bahia colonial revela o quanto os ossos humanos foram utilizados pela mística católica nos tempos coevos: a maior "santa" baiana, soror Vitória da Encarnação, a mais famosa e virtuosa religiosa do Convento do Desterro, nascida em 1661, dentre as muitas penitências que costumava praticar, além de passar noites inteiras por sobre os túmulos do claustro de seu mosteiro, rezando, chorando aos soluços e conversando longamente com as almas, certa vez desenterrou da tumba a canela de um defunto e, com esse osso na boca, percorreu o claustro em procissão numa sexta-feira santa: a canela ainda estava fétida e asquerosa, impregnando fortemente a boca e o rosto da pobre religiosa, que ficou salivando durante oito dias sem parar devido ao fedor (5).

Foi contudo nos rituais cabalísticos e de feitiçaria que encontramos maiores referências sobre a utilização de restos mortais no Brasil antigo. Nossos exemplos, encontrados nos arquivos inquisitoriais, referem-se sobretudo à capitania de Minas Gerais, e revelamnos detalhes dessas práticas macabras que vão desde sua obtenção clandestina nas sepulturas dentro dos templos até sua manipulação com outros elementos cabalísticos na composição dos recheios das famigeradas "bolsas de mandinga" e "patuás", tão comuns na piedade popular de antanho, e que por sua causa inúmeros brasileiros tiveram seus nomes denunciados junto ao Tribunal do Santo Ofício, alguns inclusive sendo presos e remetidos para Lisboa exatamente pela culpa de sua utilização.

Em 1760, chegava a denúncia à Inquisição de que na vila de Itaubira, Minas Gerais, a negra Angela Maria Gomes, da nação Courana, forra, enfamada de ser "mestre feiticeira", foi surpreendida com outras mulheres "desenterrando um defunto no adro da Igreja de Nossa Senhora da Boa Viagem", utilizando, além dos restos mortais, morcego e bode na confecção de seus feitiços, reunindo muita gente em sua casa, para os batuques que se realizavam todas as terças e sextasfeiras, religiosamente (6).

Desenterrar os restos mortais de defuntos era um dos expedientes de que os "calunduzeiros" lançavam mão para obter a matéria-prima de seus malefícios. Outros obtinham-na de procedência diversa: o escravo José Francisco Pereira, 25 anos, natural de Costa de Judá, disse que foi em Pernambuco que o feiticeiro Zamita lhe "fez a cabeça”, e que para a confecção de patuás usava sempre pedacinhos da mão de uma criança, que encontrara morta dentro de uma panela, numa praia deserta, deixando-a então
5 Jabotão, Frei Antonio de Santa Maria, Novo Orbe Seráfico Brasílico, Rio de Janeiro, Tipografia Brasileira, 1859 , p. 706

Arquivo Nacional da Torre do Tombo, Inquisição de Lisboa, Caderno do Promotor ํo 125, Itaubira, 1760 (doravante abreviado: ANTT, IL, Caderno do Promotor). 
7 Luiz Mott, "A Vida Mística e Erótica do Escravo José Francisco Pereira, 1705 1736", in Revista Tempo Brasileiro, vol. 92/93, janeiro/junho de 1988, pp. 85 104.

8 Idem, "A Inquisição na Paraíba", in Revista do Ins tituto Histórico e Geográfico Paraibano.

9 Idem, "Uma Santa African no Brasil Colonial", in $D$. O. Leitura, São Paulo, ํㅜ6, 62, julho de 1987, p. 4

10 Francisco Vidal Luna, "A Vida Quotidiana em Julgamento: Devassas em Mina Gerais", in Minas Colonial: Economia e Sociedade, São Paulo, Fipe-Pioneira, 1982, p. 83.

11 Laura de Mello e Souza, $O$ Diabo na Terra de Santa Cruz, São Paulo, Companhia das Letras, 1986, p 204.

12 ANTT, IL, Caderno do Promotor o129, Bahia, 1778 .

13 Souza, op. cit., p. 201.

14 ANTT, IL, Caderno do Promotor no 130, Rio de Janeiro, 1783.

15 ANTT, IL, Caderno do Pro motor no 129 , Mariana, 1775.

16 ANTT, IL, Caderno do Promotor no 129, Mariana, 1774. secar ao sol e dela extraindo migalhas para compor suas bolsas de mandinga (7). Por sua vez, a mulher (branca) de Cristóvão Ferreira Freire, tendeiro de molhados na capitania da Paraíba, 1768, conseguiu em sua própria casa o material humano necessário para seus feitiços: ao abortar uma sua escrava, "rasgara o ventre da criança morta e lhe tirara as tripas para as secar e fazer malefícios" (8). Se contou ou não com o beneplácito da dita negra, a documentação não informa. Curioso ter conservado tão-somente as tripas do negrinho, pois outras pessoas foram acusadas de usar o corpo inteiro para suas mandingas: Rosa Egipcíaca, então escrava da progenitora do literato frei Santa Rita Durão, antes de tornarse a fundadora do Recolhimento do Parto no Rio de Janeiro, foi acusada pelo padre Vicente Ferreira de "ser fina feiticeira e por isto viera corrida das Minas Gerais, por se lhe ter achado o corpo seco de uma criança" (9). Outras feiticeiras são acusadas na mesma capitania de possuírem escondido corpo inteiro de criancinhas: Florência do Bonsucesso "tem uma criança mirrada da qual tira carne seca e reduz a pó para com ela fazer suas feitiçarias" (10), e o negro Mateus, "que trazia consigo uma criança mirrada que tinha embruxado metida em um surrão" (11).

Não só as tripas e mãozinhas de crianças eram consideradas matéria-prima valiosa na elaboração de bruxarias: na Fazenda de Tabacos, na freguesia de São Felipe, no Recôncavo Baiano, a preta Tereza, "tida, havida, reputada e temida por feiticeira", foi acusada de ter provocado, através de suas maldades, a morte de um crioulinho de quinze dias - e como prova de sua maldade, atestaram os denunciantes terem encontrado debaixo da cama da feiticeira o umbigo seco e o cinteiro do infeliz "anjinho", embora mesmo sendo torturada a temida feiticeira negasse qualquer interferência na dita morte (12). Aliás, como muito bem lembra Laura de Mello e Souza, citando diversos autores e documentos também localizados na Torre do Tombo, "na Europa, uma das crenças mais generalizadas, no que dizia respeito às bruxas, era sua atuação como assassinas de crianças" (13), o que reforça nossa afirmação inicial de que algumas cerimônias macabras e preconceitos contra supostas feiticeiras têm origem "branca" e não "negra", embora também as gentes de cor tivessem adotado não apenas a religião como também as superstições e práticas diabólicas dos donos do poder.

Obtidos os restos mortais, seja de adultos, seja de "anjinhos", sua utilização variava de acordo com a crença do freguês. No Rio de Janeiro, em 1783, Luíza Maria Angélica, parda, solteira, tida como meretriz, dançarina e representante de teatro público - currículo dos mais invejáveis, convenhamos!-, era vista em noites de lua detrás da rua de São José, onde morava, com duas caveiras na mão, enquanto fazia suas orações (14). Freiras, frades e confrades das ordens terceiras também usavam caveiras, à imitação dos santos, para criar clima favorável às suas meditações e preces; uma meretriz dançarina, com duas caveiras na mão, altas horas da noite, sugeria mais uma orgia cadavérica do que exercício espiritual, daí ser denunciada como suspeita de pacto diabólico. A mesma suspeita recaiu sobre outra mulher parda, Feliciana de Oliveira, moradora no bispado de Mariana, que em 1775 foi acusada de todas as sextas-feiras ter o costume de atar sua escrava crioula Maria com uma fita verde, desenhando uma cruz no chão da varanda, introduzindo dois ossos de defunto na boca da escrava, mandando-a pôr o pé por sobre a cruz enquanto recitava as seguintes palavras malsoantes: "Joaquim, Joaquim, largue sua mulher e filhos por mim..." (15). Novamente aqui, embora o gesto seja o mesmo da maior santa baiana, soror Vitória da Encarnação, o ritual e os objetivos são notoriamente opostos e destinados a fins profanos, senão demoníacos, quando menos supersticiosos.

Na mesma Mariana, 1774, outra parda, Albina Maria, dizia que sua senhora, Josefa Maria Soares, tinha guardado em casa duas caveiras: uma enterrada na porta de sua moradia para proteger a família e afastar os maus agouros, e outra conservada escondida dentro de casa, da qual retirava de quando em quando alguns ossinhos, que, triturados até tornarem-se pó, eram depois misturados às comidas daqueles a quem desejava enfeitiçar, seja para conseguir-lhes o amor, serviços sexuais ou causar-lhes malefícios (16). 


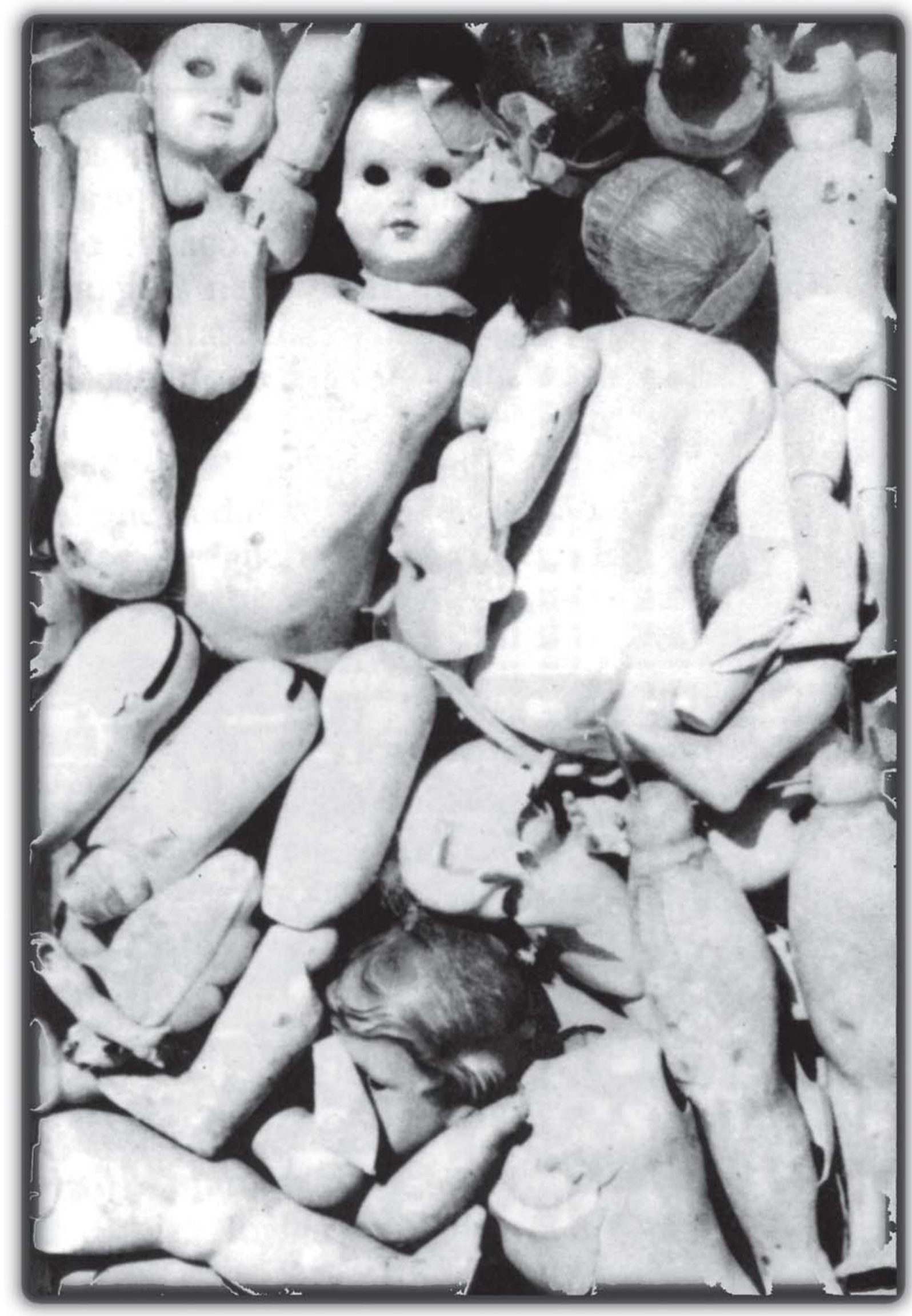


17 ANTT, IL, Caderno do Promotor no 130 , São Miguel, 1782

18 ANTT, IL, Caderno do Promotor no 129, Santos, 1776.

19 ANTT, IL, Processo no 14.649 , reprodução fotográfica dos desenhos deste mandingueiro fol publicada na revista Religião e Sociedade, ㄲo12 (Rio de Janeiro, 1985).

20 Michael Kunze, A Caminho da Fogueira, Rio de Janeiro, Campos, 1989, pp. 179 82. Agradeço a indicação desta referência à ilustre folclorista e amiga Zita Tavares de Lima.

21 José Vieira Fazenda, "Antiqualhas e Memória do Rio de Janeiro", in Re vista do Instituto Histórico e Geográfico Brasileiro, n 143, 1921
No mesmo bispado, na vila de São Miguel, no ano de 1782, é a vez de serem denunciados os mulatos Joaquim e Clemência, escravos, aos quais se atribuía a feitura de feitiços com saliva, cabelo, unhas e outras substâncias cabalísticas, "temperando-os com pós, unhas e carnes de defuntos que iam tirar nas sepulturas das igrejas, e metiam aqueles feitiços na casca de um caramujo, e, quando queriam que a pessoa padecesse, mudavam os caramujos de um lugar para o outro", espetando-os com alfinetes e agulhas, para atingir com igual dor a seus inimigos (17).

Até agora tais exemplos, com exceção da senhora branca de Mariana, utilizaram-se de restos mortais quer como parafernália de ritos mágicos, quer como reforço em poções mágicas, sempre exteriores porém aos agentes ou vítimas. Temos evidências, contudo, da utilização de partes cadavéricas como ingrediente de certos malefícios que se destinavam a penetrar no corpo da pessoa a quem se pretendia atingir: na vila de Santos, capitania de São Paulo, 1776, o negro Filipe, escravo possesso pelo Demônio, só se acalmava de suas diabruras quando o exorcista aplicavalhe os preceitos do Ritual Romano, sendo acusado junto ao comissário do Santo Ofício de sua freguesia de ter usado dente de jacaré e pó de defunto na preparação de uma potagem que dera a seu senhor, provocando-lhe insuportáveis dores nas cadeiras e barriga - cuja finalidade, segundo depois confessou o energúmeno, era secar as tripas do enfeitiçado. Ao revistarem uma bolsa do cativo, nela encontraram um dedo de criança, unhas e um osso de defunto (18).

Também dentro de um saquinho de pano do preto forro Matias Gonçalves Guizando, alfaiate morador em Recife, preso nas cadeias da Câmara local em 1806 - nos extertores da existência do Terribilem Tribunalem da Inquisição -, encontraramse, além de cinco orações proibidas e vários desenhos representando diabos e símbolos cabalísticos, nada menos que dez pedaços de ossos de um crânio humano, destinados a compor os malefícios que costumeiramente lhe encomendavam (19).

Crânios, ossos, sobretudo mãozinhas e dedos de crianças, eram os restos mortais mais valorizados por quantos acreditassem no poder das bruxarias e malefícios. Valorização importada também esta da Europa: conforme ensinou nosso já conhecido bruxo espanhol de Logronho, quando sua seita ia desenterrar os mortos no escuro das igrejas, "a luz que levam é uma acha feita do braço esquerdo inteiro de uma criança que tenha morrido sem ter sido batizada e acendem-no pela parte dos dedos, e dá luz como se fora um tocha". Essa curiosa superstição, segundo ensina Michael Kunze, teve ampla divulgação por toda a Europa, notadamente na Baviera, onde encontrou a crendice da "vela de ladrão", isto é, a utilização de dedinhos de crianças, de preferência pagãs, quer como ingrediente nas bruxarias, quer como tocha de iluminação. Segundo este autor, tais práticas seriam oriundas ainda dos tempos do paganismo (20).

Alguns dos feiticeiros e calunduzeiras do Brasil colonial aqui já citados referiram-se à utilização de mãos ou dedos de crianças como ingrediente principal de seus malefícios. Por que a fixação particular nessas partes, não encontramos explicação. Talvez pela facilidade em sua remoção do corpo, quer ao ser sepultado, quer quando desenterrado furtivamente do adro das igrejas, ou do campo santo. Lembramo-nos aqui da extração piedosa de uma relíquia do mais venerado santinho do Rio de Janeiro, falecido em 1747, frei Fabiano de Cristo, franciscano do Convento de Santo Antonio, no Alto do Largo da Carioca. Numerosa turba acorreu a dar o último adeus ao santo fradinho, e não satisfeitos os fiéis em cortarem pedacinhos de seu hábito, cordão, fios de cabelo, um devoto mais afoito e sequioso de relíquia mais substantiva cortou um dedo do pé de frei Fabiano, proeza realizada sem que frade algum do velório tivesse prestado atenção (21).

Hoje em dia, ao menos na Bahia, permanece entre a população a crença de que dedo de anjinho constitui elemento privilegiado para dar sorte e fortuna a quantos dele se utilizem. Entrevistando algumas pessoas, entre negros e brancos de diferentes classes sociais e variegada idade, todos confirmaram a informação de que o povo diz que "dedo de anjo dá sorte", sobretudo na venda de acarajés. Suspeitam muitos que as baianas que têm seus 
tabuleiros muito freqüentados por numerosa clientela ou usaram um dedinho de criança para mexer suas panelas de quitutes, ou têmno escondido debaixo da toalha, num canto oculto do tabuleiro. Contaram-me ainda que na cidade de Amargosa, no agreste baiano, anos atrás, num concorrido "caruru" oferecido por tradicional terreiro de Candomblé, um comensal encontrou dentro de seu prato nada mais nada menos que um dedinho de criança - se branco ou preto, não me souberam dizer. Em nenhum desses episódios, contudo, nem a leve suspeita de que tais criancinhas tivessem sido sacrificadas ritualmente, para daí extrairlhes mão, tripas ou o dedinho: já eram cadáveres quando amputaram-lhes essas partes.

Concluímos este relato macabro referindo outro costume encontrado no Brasil antigo, praticado por brancos, negros e mestiços, relacionado não à utilização de restos mortais, mas de objetos fúnebres, como ingredientes para sortilégios ou malefícios. Também estes certamente têm sua inspiração em feitiçarias medievais oriundas do Velho Mundo, tanto que no famoso Grande e Verdadeiro Livro de São Cipriano estão arroladas algumas mágicas e bruxarias desse teor. Por exemplo: "A feitiçaria que se faz com cinco pregos tirados de um caixão de defunto quando já tenha saído da sepultura"; ou "Feitiçaria que se pode fazer com malvas colhidas no cemitério ou no adro de uma igreja"; ou ainda "A mágica da agulha passada três vezes por um defunto" (22). Nos arquivos inquisitoriais alguns feiticeiros foram denunciados por sortilégios semelhantes: o já citado mandingueiro José Francisco Pereira, nativo da Costa da Mina, além de confessar diversas e multiformes cópulas com Satanás, seja na figura de formosa manceba, seja de fogoso varão, disse que tinha o costume de usar agulha de coser mortalha de defunto para "costurar" a pele da palma da mão ou a sola dos pés de quantos o procuravam com o intuito de gozar boa sorte nos jogos de azar. Certamente deve ter aprendido tal "simpatia" nas Minas Gerais, pois pelo visto era generalizada a crendice dos poderes de tais agulhas. A crioula forra Maria Caetana de Oliveira revelou que o branco Manuel Afonso Galvão, de Mariana, lhe ensinara que não havia remédio mais eficaz para manter seu homem preso a si do que pregar uma linha em sua roupa, costurada com agulha que tivesse amortalhado um defunto (23). Crença espalhada por todo o território colonial, e documentada desde o século XVII, tanto que em Porto Calvo, capitania de Pernambuco, o pardo Antão de Escócia fora preso, em 1682, exatamente por ter entre seus pertences, além de orações proibidas e uma lasquinha de pedra dara, também "uma agulha que amortalhou defuntos" (24). Perguntando eu à minha velha empregada, Carlita Chaves, neta de africanos, moradora no Bogum (onde está o famoso "vodum" Gêge), o que sabia sobre tais crendices, disse que de fato, nos tempos de sua avó, quando iam fazer a mortalha para algum defunto, costuravam-na com agulha virgem, a qual era depois muito bem guardada "para remédios de muita serventia".

Ainda outro episódio envolvendo condutas heterodoxas em matéria de devoção foi registrado em Serinhaém, Pernambuco, em 1762: a acusada é uma preta forra, Tereza de Barros, que foi vista recitando rezas proibidas vestida em trajes de defunto, rodeada de muitas velas acesas (25).

Tais são as evidências documentais descobertas notadamente na Torre do Tombo de Lisboa, que nos ensinam sobre a utilização de restos mortais em diferentes sortes de "feitiçarias" no Brasil antigo. Que sirvam de álibi contra os que caluniosa e preconceituosamente acusam as religiões afro-brasileiras de praticarem sacrifícios de crianças. Se porventura hodiernamente comprovar-se que tal ou qual seita religiosa sacrificou seres humanos para seus rituais, tais episódios devem merecer nossa mais completa repulsa e ser alvo de rigorosa investigação policial, seja praticada por cristãos, candomblezeiros ou quaisquer outras denominações. Relativamente ao "culto do macabro" (26), não há como negar sua origem "branca", resquício dos tempos medievais: de um lado, a vertente abençoada, representada pelo culto às relíquias dos santos, do outro, a feitiçaria, tendo como matéria-prima restos mortais humanos manipulados com fins mágicos, maléficos ou benéficos, mas considerados heterodoxos pelos herdeiros do Santo Ofício.
22 O Grande e Verdadeiro Livro de São Cipriano, s/a, Rio de Janeiro, Científica, s/d.

23 ANTT, IL, Caderno do Promotor no 130, Mariana, 1770

24 ANTT, IL, Caderno do Promotor ํㅡ 58, Porto Calvo, 1682

25 ANTT, IL, Caderno do Promotor no 126, Serinhaém, 1762 .

26 Adalgisa Arantes Campos, "A Presença do Macabro na Cultura Barroca", in Revista do Departamento de História, oㅜ 5, dezembro de 1987, pp. 83-90. 